\title{
Clinicohistopathological Characteristics of Malignant Melanoma in the Gall Bladder: A Case Report and Review of the Literature
}

\author{
Schmidt Adrian (D), ${ }^{1}$ Caspar Clemens, ${ }^{2}$ Schmidt-Weiss Elisabeth, ${ }^{3}$ and Stadlmann Sylvia ${ }^{4}$ \\ ${ }^{1}$ Department of Internal Medicine, Division of Medical Oncology and Hematology, Triemli Hospital, Birmensdorferstrasse 497, \\ 8063 Zurich, Switzerland \\ ${ }^{2}$ Department of Internal Medicine, Division of Medical Oncology and Hematology, Cantonal Hospital Baden, Im Ergel 1, \\ 5404 Baden, Switzerland \\ ${ }^{3}$ Centre for Hematology and Oncology, Clinic of Medical Oncology, University Hospital Zurich, Rämistrasse 100, \\ 8091 Zürich, Switzerland \\ ${ }^{4}$ Division of Pathology, Cantonal Hospital Baden, Im Ergel 1, 5404 Baden, Switzerland
}

Correspondence should be addressed to Schmidt Adrian; adrian.schmidt@bluewin.ch

Received 2 August 2017; Revised 9 January 2018; Accepted 16 January 2018; Published 20 March 2018

Academic Editor: Piero Tosi

Copyright (c) 2018 Schmidt Adrian et al. This is an open access article distributed under the Creative Commons Attribution License, which permits unrestricted use, distribution, and reproduction in any medium, provided the original work is properly cited.

Objective. Primary gall bladder melanoma is a rare and controversial entity. So far, only 36 cases are documented in the literature. Metastatic melanoma targeting the gall bladder, however, has been reported to occur in about $15-20 \%$ of melanoma patients and is much more common. Methods. Based on the case of a 58-year-old woman presenting with multiple melanoma nodules in the gall bladder, we searched in the available literature in PubMed for articles describing a "primary melanoma of the gallbladder" regardless of language used. Results. We detected 33 papers that described 36 cases of primary gall bladder melanoma between 1907 and 2017. From different criteria distinguishing primary and secondary gall bladder melanoma, generally, the following were accepted: (1) exclusion of previous primary melanoma, (2) absence of synchronous involvement of other sites, (3) unicity of the lesion, (4) polypoid or papillary shape of the lesion, and (5) presence of junctional melanocitary component. Review of the 36 published cases revealed that only about one-fourth of them fulfilled all the five criteria. Conclusion. Primary gall bladder melanoma is even rarer than described in the literature, and the question whether this entity really exists remains open.

\section{Introduction}

The existence of a primary melanoma of the gall bladder is controversial, and only about 40 cases are described in the literature so far. Based on an own case with diagnosis of a melanoma in the gall bladder, we were wondering which criteria should be fulfilled for this diagnosis, how they are able to separate this entity from metastatic melanoma, and how these criteria would match with the formerly reported cases as well as with the history of our own patient.

\section{Case Report}

A 58-year-old Caucasian woman presented at our institution with immobilizing back pain, known for 4 years but exacerbating for 3 months. The past history included smoking (about 15 pack-years), appendectomy and tonsillectomy as a child, and extensive endometriosis which required surgical excision of sigmoid colon and hysterectomy sixteen years earlier. Conventional X-rays of the thoracic and lumbar spine revealed degenerative alterations only. However, magnetic resonance imaging (MRI) demonstrated multiple lesions in all vertebral bodies with a pathologic fracture in the 8th thoracic vertebral body. Blood count was completely normal. Suspecting bone metastases of a yet unknown primary tumour, a thoracoabdominal CT scan was performed, revealing disseminated small nodules in both lungs (max. 1.0 $\times 0.5 \mathrm{~cm}$ in diameter) and small polypoid intraluminal lesions in the gall bladder infiltrating the liver (Figure 1), the latter showing additionally some very small lesions measuring only a few millimeters in diameter. An ultrasound confirmed a 


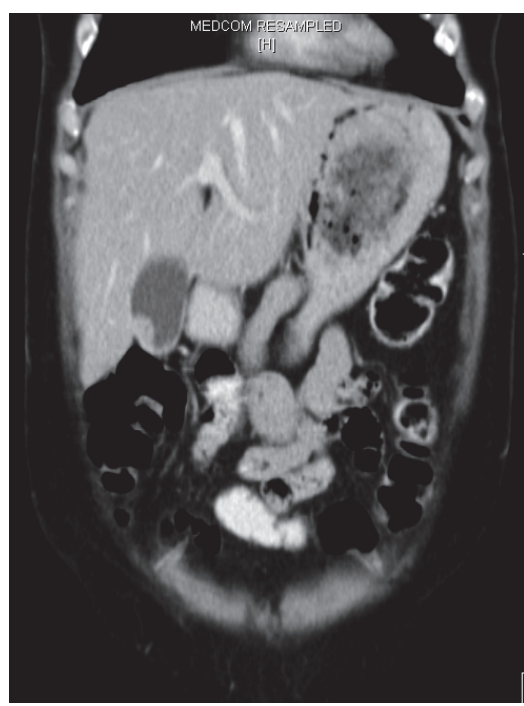

Figure 1

solid tumour mass in the fundus of the gall bladder, highly suspicious for primary gall bladder cancer. Upper endoscopy and lower endoscopy were inconspicuous. External biopsies of a suspected pulmonary lesion and the thickened conglomerate of gall bladder wall towards liver were both not diagnostic. Repeating one of these interventions seemed not promising. Palliative radiotherapy $(5 \times 4 \mathrm{~Gy})$ of the thoracic spine was performed. Unfortunately, severe mood depression and panic attacks occurred, delaying further diagnostic and therapeutic interventions. Six weeks later, a repeated CT scan revealed progression of the bone lesions and significant thickening of the gall bladder wall. MRI did not detect brain metastases. For further diagnosis, we discussed with the patient pulmonary wedge resection, vertebral biopsy, or cholecystectomy. With the two unsuccessful attempts in mind, she chose the latter procedure, suggesting the highest probability to finally reach a diagnosis. This intervention was then performed without complications and provided the following findings.

Macroscopically, the gall bladder specimen was $9 \mathrm{~cm}$ long and $3 \mathrm{~cm}$ in diameter. In the lumen, a friable broad based papillary nodule in the fundus $(5 \mathrm{~cm}$ maximum diameter) and two polypoid satellite nodules in the neck $(1 \mathrm{~cm}$ maximum diameter) were present. In the cystic duct, a small gallstone was identified. Histopathologically, surprisingly, the nodules corresponded to a malignant melanoma. The tumour was almost completely confined to the mucosa (Figure 2(a)) with only focal invasion of the muscularis propria and subserosa. It was composed of pigmented polygonal cells with vesicular nuclei and prominent eosinophilic nucleoli (Figure 2(b)). Numerous mitotic figures could be encountered. The lining of the villi of the gall bladder mucosa consisted of tall columnar cells with in-between lying pigmented neoplastic cells and macrophages (Figure 2(c)). Junctional activity, meaning presence of microscopic aggregates of melanoma cells at the junction of epithelium and lamina propria, was present (Figure 2(d)). Tumour cells stained positively for S100, HMB45,
Melan A, and CD117 by immunohistochemistry and melanin pigment with Fontana-Masson stain. Neither PDGFRA nor kit mutations were detected.

As neither BRAF inhibitors nor checkpoint inhibitors were yet available in clinical practice, a palliative chemotherapy with temozolomide $\left(200 \mathrm{mg} / \mathrm{m}^{2}\right.$ daily for 5 days $)$ and monthly infusions of zoledronic acid were installed. Temozolomide was preferred to the former standard of care Dacarbazine, as equal efficacy was demonstrated [1] and the oral application convened to the patient.

Unfortunately, the patient developed severe myelosuppression CTCAE grade 4, requiring several transfusions of erythrocytes and platelets, as well as the application of G-CSF. Another CT scan performed after first chemotherapy cycle showed progression of the lung and liver metastases, newly developed spleen metastases, and pathologic fractures of the lumbar spine on levels 3 and 5. Because of the severe side effects without rendering any effect on tumour progression, the patient refused another series of palliative radiotherapy as well as another attempt of systemic therapy and decided to look for alternative treatment regimens. Two months later, she presented again with exacerbating bone pain, severe anemia (hemoglobin: $5.8 \mathrm{~g} / \mathrm{dl}$ ), and thrombocytopenia (36 G/l) as a result of progressive bone marrow infiltration. After installation of an analgesic therapy, the patient was transferred to a hospice institution, where she died a few days later.

\section{Review of the Literature}

Malignant melanoma in the gall bladder is rare. It usually represents a metastasis from a primary skin or mucosal melanoma and has been reported to occur in $15-20 \%$ of melanoma patients $[2,3]$. Primary melanoma of the gall bladder is even much rarer with only 36 cases documented in the literature so far [4-36]. 15 (41.7\%) of the reported patients were men and 21 (58.3\%) were women. This corresponds to a male to female ratio of 0.71 ; range of age was 25 to 75 years at the time of diagnosis (median: 51.5 years). In none of the reported cases, a primary skin or mucosal melanoma could be identified. 27 of 31 (87.1\%) evaluable patients initially presented with abdominal pain. 21 of $30(70.0 \%)$ patients had symptoms of acute cholecystitis, demonstrating calculi in only 4 of $33(12.1 \%)$ patients. Isolated tumours in the gall bladder without synchronous involvement of other organs at the time of diagnosis occurred in 22 of 35 (62.8\%) patients. Unicity of the intraluminal gall bladder tumour was present in 25 of $35(71.4 \%)$ patients. The median tumour size was $2.35 \mathrm{~cm}$ (range: $0.9-10 \mathrm{~cm}$ ). 9 of $17(52.9 \%)$ tumours were located in the fundus, 8 of 18 (44.4\%) in the corpus, and/or 6 of $18(33.3 \%)$ in the neck of the gall bladder. 12 of $25(48.0 \%)$ tumours were pedunculated and $13(52.0 \%)$ were broad based. 11 of $23(47.8 \%)$ tumours infiltrated the muscularis propria and 3 of $18(16.7 \%)$ and 4 of $21(19.0 \%)$ cases additionally showed subserosal and/or serosal involvement. In 3 of $31(9.7 \%)$ patients, malignant melanoma of the gall bladder resulted in perforation and acute peritonitis. Histomorphologically, the vast majority of melanoma cells exhibited epithelioid morphology (84.0\%); $33.3 \%$ of cases had additional or exclusive sarcomatoid growth pattern. 29 of 


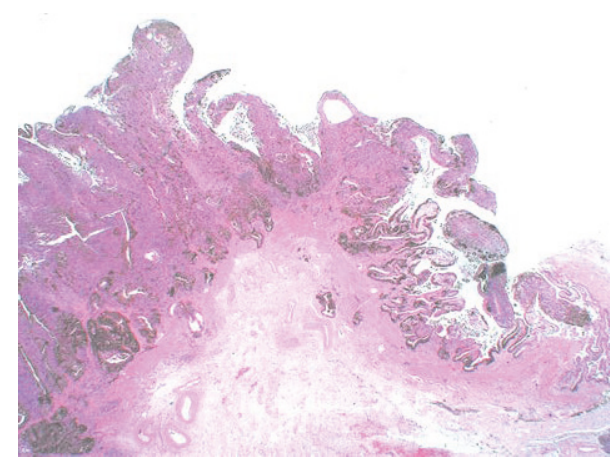

(a)

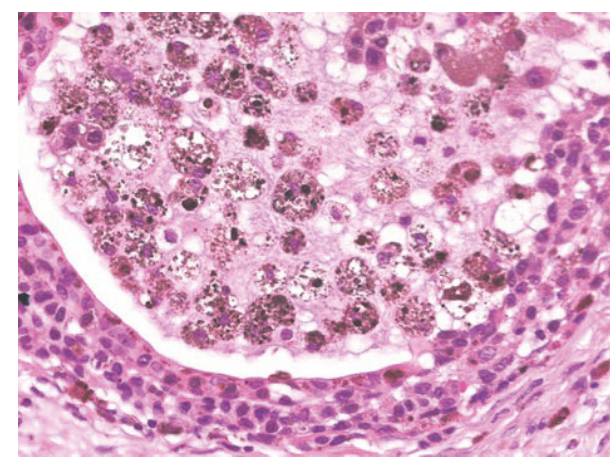

(c)

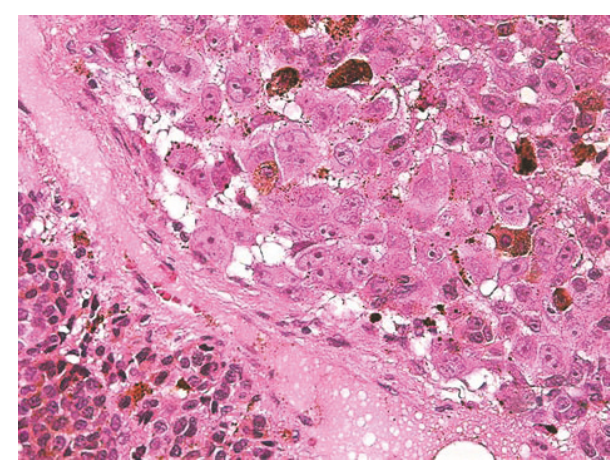

(b)

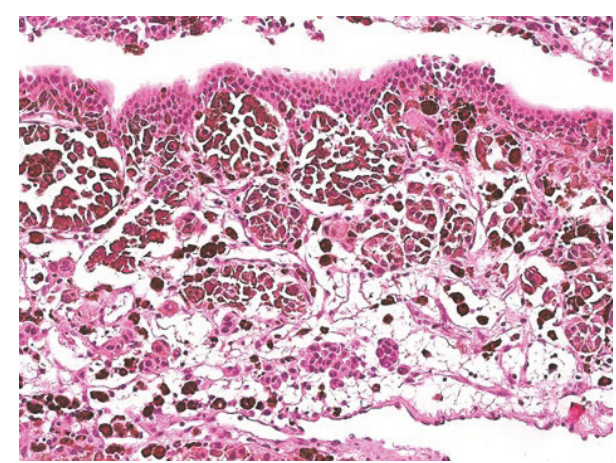

(d)

FIGURE 2

the $36(80.6 \%)$ patients had cholecystectomy. 6 of $34(17.6 \%)$ patients additionally received chemotherapy and $3(8.8 \%)$ received radiotherapy. 11 of $33(33.3 \%)$ patients developed lymph node metastases and 22 of 36 (61.1\%) developed hematogenous metastases. 18 of $21(85.7 \%)$ patients died of disease within 0.2 to 168 months after primary diagnosis (median: 9.0 months).

\section{Discussion}

Whether primary malignant melanoma of the gall bladder exists is controversial [32, 37]. Objective criteria for distinguishing primary melanoma of the gall bladder from metastatic melanoma include (1) exclusion of previous primary melanoma, (2) absence of synchronous involvement of other sites, (3) unicity of the lesion, (4) polypoid or papillary shape of the lesion, and (5) presence of junctional melanocitary component [38]. The presence of the latter has been described to be the most important diagnostic clue for primary gall bladder melanoma. However, in some reports of clearly melanoma metastases, histopathologically, a junctional activity was also detectable. Of the reported cases in the literature, only 8 of 29 meticulously documented patients $(27.6 \%)$ fulfilled all of these 5 criteria. In our patient, junctional change at the tumour margin and a polypoid shape of the lesion could be clearly demonstrated. However, the presence of multiple tumour nodules in the gall bladder and synchronous involvement of other organs at the time of diagnosis favour a metastatic process. Reviewing the past history of our patient in fact revealed excision of a thoracic dysplastic nevus in an external hospital thirteen years earlier. Regarding clinicohistopathological findings, primary and secondary gall bladder melanomas share a remarkable similarity [18]. Based on our own and the reported data, a diagnosis of gall bladder melanoma should be favoured if (a) the patient has recurrent abdominal pain with symptoms of acute cholecystitis, (b) there is no evidence of cholecystolithiasis (which distinguishes it from gall bladder cancer), and (c) MRI or ultrasound reveals a polypoid intraluminal tumour confined to the gall bladder mucosa. The number of suspected primary gall bladder melanomas that withstand an accurate verification is very small, and it remains questionable if this entity really exists. Independently, surgical excision of suspected isolated gall bladder melanoma is mandatory.

\section{Conflicts of Interest}

The authors declare that they have no conflicts of interest.

\section{References}

[1] M. R. Middleton, J. J. Grob, N. Aaronson et al., "Randomized phase III study of temozolomide versus dacarbazine in the treatment of patients with advanced metastatic malignant melanoma," Journal of Clinical Oncology, vol. 18, no. 1, pp. 158166, 2000.

[2] T. K. Dasgupta and R. D. Brasfield, "Metastatic melanoma of the gastrointestinal tract," Archives of Surgery, vol. 17, pp. 1323-1339, 1964. 
[3] J. E. Meyer, "Radiographic evaluation of metastatic melanoma," Cancer, vol. 42, no. 1, pp. 127-132, 1978.

[4] Wieting and Hamdi, Über die physiologische und pathologische Melaninpigmentierung und den epithelialen Ursprung der Melanoblastome: Ein primäres Melanoblastom der Gallenblase, Beitr Path anat;42:23-84, 1907.

[5] S. R. Rosenthal, "Primary melanocarcinoma of the gallbladder," American Journal of Cancer, vol. 15, no. 3, pp. 2288-2300, 1931.

[6] E. E. Pautler and E. M. Gallavan, "Melanoma of brain and gallbladder," AMA Archives of Pathology, vol. 51, no. 2, pp. 238245, 1951.

[7] T. S. Walsh, "Primary melanoma of the gallbladder with cervical metastasis and fourteen and a half year survival. First histologically proved case," Cancer, vol. 9, no. 3, pp. 518-522, 1956.

[8] C. H. Jones, "Malignant melanoma of the gall-bladder," The Journal of Pathology, vol. 81, no. 2, pp. 423-430, 1961.

[9] E. C. Raffensperger, F. W. Brason, and G. Treano, "Primary melanoma of the gallbladder," American Journal of Digestive Diseases, vol. 8, no. 4, pp. 356-363, 1963.

[10] H. Debiec, K. Kirylowicz, and Z. Herba, Dwa przypadki czerniaka ziosliwego pecherzyka zolciowego, Przeglad Lekarski,4635, 1966.

[11] C. I. Simard, P. George, T. Caulet, and J. Diebold, "Les mélanoms malins de la vésicule biliare," Journal de Chirurgie, pp. 51-58, 1966.

[12] B. Peison and L. Rabin, "Malignant melanoma of the gallbladder. Report of three cases and review of the literature," Cancer, vol. 37, no. 5, pp. 2448-2454, 1976.

[13] J. L. Sierra-Callejas and K. Warecka, "Primary malignant melanoma of the gallbladder," Virchows Archiv A: Pathological Anatomy and Histology, vol. 370, no. 3, pp. 233-238, 1976.

[14] Y. Hatae, M. Kikuchi, M. Segawa, and K. Yonemitsu, "Malignant Melanoma of the Gallbladder," Pathology - Research and Practice, vol. 163, no. 3, pp. 281-287, 1978.

[15] G. Carle, A. M. Lessells, and P. V. Best, "Malignant melanoma of the gallbladder: A case report," Cancer, vol. 48 , no. 10, pp. 23182322, 1981.

[16] C. Baumann, P. Petropoulos, and P. Hahnloser, "Le melanoma malin de la vésicule biliare," Rev Med Suisse Romande, pp. 102903, 1982.

[17] J. B. Anderson, R. C. N. Williamson, and R. G. Hughes, "Malignant melanoma of the gallbladder," Postgraduate Medical Journal, vol. 59, no. 692, pp. 390-391, 1983.

[18] S. R. Borja, W. R. Meyer, and J. P. Cahill, "Malignant melanoma of the gallbladder. Report of a case," Cancer, vol. 54, no. 5, pp. 929-931, 1984.

[19] S. E. Naguib and K. Atermann, "Presumed primary malignant melanoma of the gallbladder. Report of a case and a review of the literature," The American Journal of Dermatopathology, pp. 231-243, 1984.

[20] B. Seul and H. Lüchtrath, "Malignes Melanom der Gallenblase," Der Chirurg, vol. 55, pp. 179-181, 1984.

[21] A. Rudolph, J. Bothe, and U. Bonk, "Malignes Melanom der Gallenblase," Der Chirurg, vol. 56, pp. 469-471, 1985.

[22] J. J. Verbanck, L. J. Rutgeerts, F. J. Van Aelst et al., "Primary malignant melanoma of the gallbladder, metastatic to the common bile duct," Gastroenterology, vol. 91, no. 1, pp. 214-218, 1986.

[23] D. I. Heath and C. Womack, "Primary malignant melanoma of the gall bladder," Journal of Clinical Pathology, vol. 41, no. 10, pp. 1073-1077, 1988.
[24] A. Guerini, D. Gottardi, A. Galassi, A. Armani, L. Biondani, V. Candiani et al., "Malignant melanoma of the gallbladder," Archives Danatomie Et De Cytologie Pathologiques, pp. 168-170, 1990.

[25] J. O. Habeck, "Primäres Melanom der Gallenblase," Zentralblatt Fur Pathologie, vol. 139, pp. 367-371, 1993.

[26] N. Hatanaka, M. Miyata, W. Kamiike et al., "Radical resection of primary malignant melanoma of the gallbladder with multiple metastases: Report of a case," Surgery Today, vol. 23, no. 11, pp. 1023-1026, 1993.

[27] A. F. Velez, R. B. Penetrante, J. E. Spellman Jr., A. Orozco, and C. P. Karakousis, "Malignant melanoma of the gallbladder: Report of a case and review of the literature," The American Surgeon, vol. 61, no. 12, pp. 1095-1098, 1995.

[28] D. Longwitz, H. C. Schulz, and A. Bosse, "Malignant melanoma of the gallbladder," European Journal of Ultrasound, vol. 17, no. 4, pp. 195-198, 1996.

[29] X. D. Dong, P. DeMatos, V. G. Prieto, and H. F. Seigier, "Melanoma of the gallbladder: a review of cases seen at Duke University Medical Center," Cancer, vol. 85, no. 1, pp. 32-39, 1999.

[30] P. De Simone, P. Mainente, and N. Bedin, "Gallbladder melanoma mimicking acute acalculous cholecystitis.," Surgical Endoscopy, vol. 14, no. 6, p. 593, 2000.

[31] R. Ricci, N. Maggiano, M. Martini et al., "Primary malignant melanoma of the gallbladder in dysplastic naevus syndrome," Virchows Archiv, vol. 438, no. 2, pp. 159-165, 2001.

[32] V. B. Simonenko, L. B. Beliaev, M. A. Makanin, A. Lyanin, and A. Promow, "Skorobozamow E, Primary melanoma of the gallbladder," Klinicheskaia Meditsina, pp. 69-71, 2004.

[33] M. Safioleas, E. Agapitos, K. Kontzoglou et al., "Primary melanoma of the gallbladder: Does it exist? Report of a case and review of the literature," World Journal of Gastroenterology, vol. 12, no. 26, pp. 4259-4261, 2006.

[34] J. Gligorijevic, V. Zivkovic, B. Djordjevic, and I. Dimov, "Primary gallbladder melanoma in dysplastic nevus syndrome: Report of case and literature review," The Turkish Journal of Gastroenterology, vol. 22, no. 6, pp. 626-630, 2011.

[35] V. Pitlovic, F. Latic, H. Pitlovic, M. Rupcic, and D. Jurisic, Latic A, Primary malignant melanoma of gallbladder. Med Glas Ljek komore Zenicko-doboj kantona, 8, 71-3, 2011.

[36] M. F. Haskaraca, M. Ozsoy, I. Özsan, and K. Kurt, "Primary malignant melanoma of the gallbladder: A case report and review of the literature," Case Reports in Surgery, vol. 2012, 4 pages, 2012.

[37] C. M. Higgins and G. M. Strutton, "Malignant melanoma of the gall bladder - does primary melanoma exist?” Pathology, vol. 27, no. 4, pp. 312-314, 1995.

[38] A. C. Allen and S. Spitz, "Malignant melanoma. A clinicopathological analysis of the criteria for diagnosis and prognosis," Cancer, vol. 6, no. 1, pp. 1-45, 1953. 


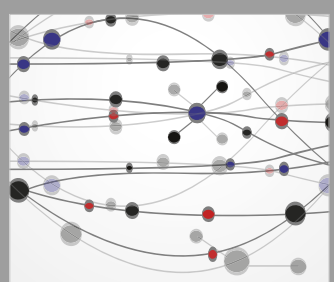

The Scientific World Journal
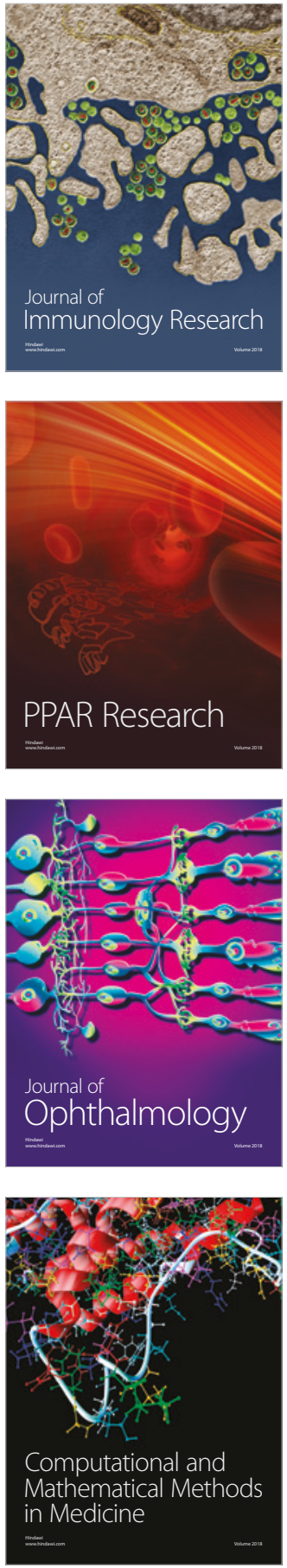

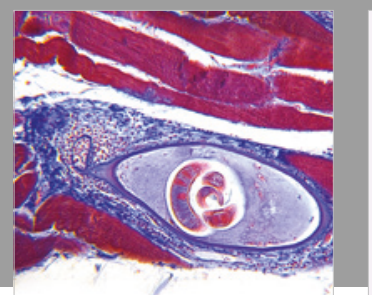

Gastroenterology Research and Practice

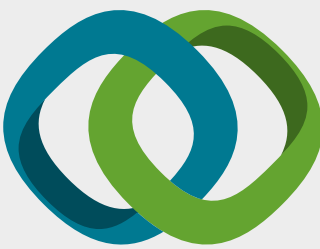

\section{Hindawi}

Submit your manuscripts at

www.hindawi.com
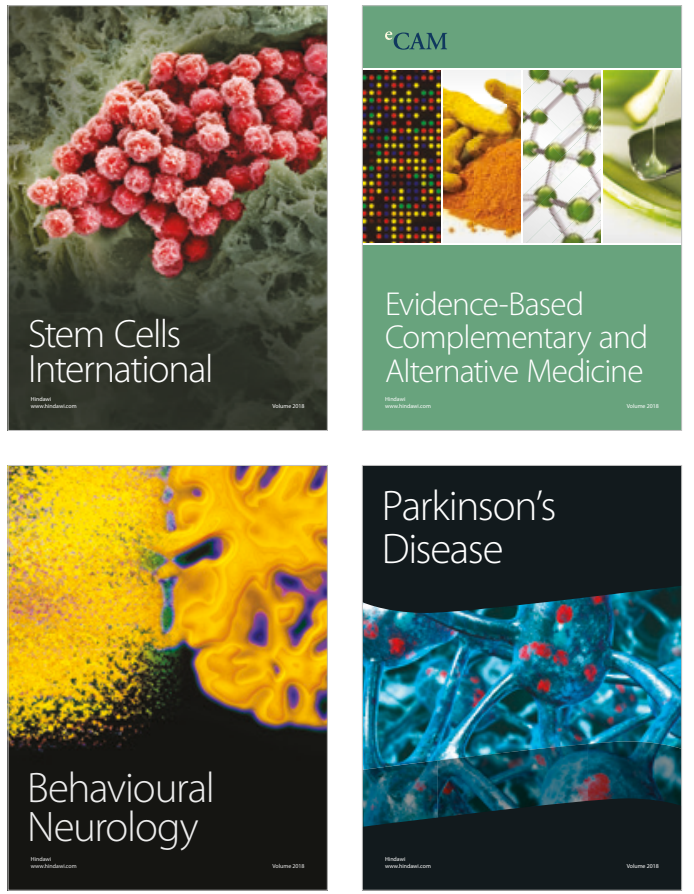

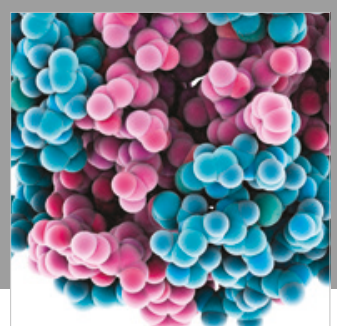

ournal of

Diabetes Research

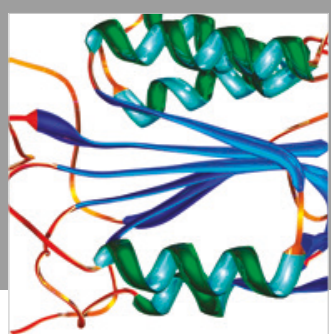

Disease Markers
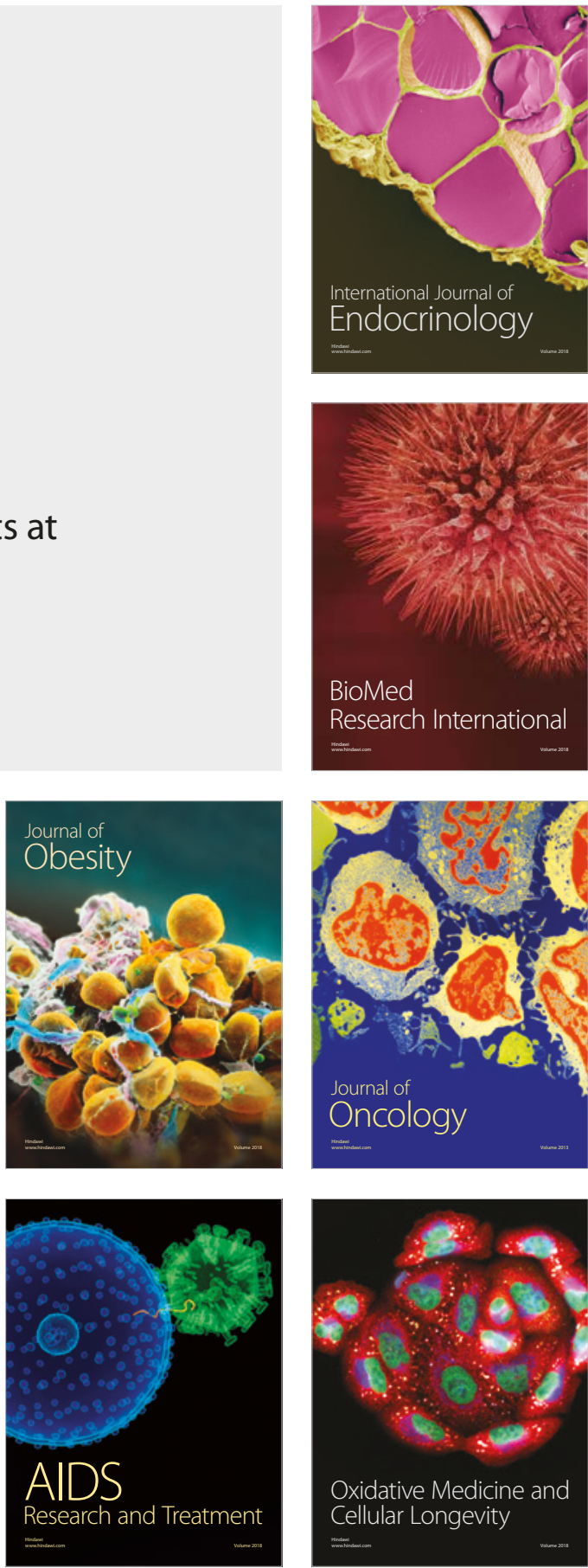